\title{
Investigation of the behavior of gadolinium complexes in plastic scintillators
}

\author{
E.S.Velmozhnaya, A.I.Bedrik, P.N.Zhmurin, \\ V.D.Titskaya, A.F.Adadurov, D.S.Sofronov

\begin{abstract}
Institute for Scintillation Materials, STC " Institute for Single Crystals", National Academy of Sciences of Ukraine, 60 Lenin Ave., 60001 Kharkiv, Ukraine
\end{abstract}

Received February 28, 2013

\begin{abstract}
This paper presents results on investigation of characteristics of plastic scintillators that contain carboxylates of aliphatic-aromatic acid with different neutral ligands as Gd-containing compounds. The peculiarities of these compounds synthesis were shown. The compounds thermal stability and solubility in styrene were investigated. Optimal conditions for Gd-containing polystyrene-based scintillators obtaining were developed.
\end{abstract}

Представлены результаты исследований характеристик пластмассовых сцинтилляторов, которые в качестве гадолинийсодержащих соединений содержат карбоксилаты жирноароматических кислот с различными нейтральными лигандами. Показаны особенности синтеза этих соединений, исследованы их термическая устойчивость и растворимость в стироле, а также разработаны оптимальные условия получения гадолиний содержащих сцинтилляторов на основе полистирола.

Дослідження поведінки комплексів гадолінію у пластмасових сиинтиляторах. О.С.Вельможна, О.І.Бедрик, П.Н.Жмурін, В.Д.Тицька, О.Ф.Ададуров, Д.С.Софронов.

Представлено результати досліджень характеристик пластмасових сцинтиляторів, які в якості гадолінійвміщуючих сполук містять карбоксилати жирноароматичних кислот з різними нейтральними лігандами. Показано особливості синтезу цих сполук, досліджено іх термічну стійкість і розчинність у стиролі, а також розроблено оптимальні умови одержання гадолінійвміщуючих сцинтиляторів на основі полістиролу.

\section{Introduction}

Plastic scintillators (PS) containing heavy metals can be used in scintillation technique for neutrons detection. Obviously, gadolinium isotopes with high cross section of thermal neutron capture are the most promising in this field of research $\left({ }^{155} \mathrm{Gd}\right.$ capture cross section is $6.1 \cdot 10^{4}$ barn, ${ }^{157} \mathrm{Gd}$ $-2.6 \cdot 10^{5}$ barn). It is possible to put them in a polymer matrix in the form of inorganic or organic compounds. Gadolinium nitrates and chlorides are usually used as inorganic compounds, but application of inorganic salts is limited due to their poor solubility in organic solvents. Therefore, for obtaining scintillator with metal-con- taining inorganic salts, emulsifiers or surfactants with hydrophilic and hydrophobic groups must be added in the system. The main characteristics of scintillators based on metal nitrates are unstable over time. $\beta$-Diketonate complexes, various crown ethers and carboxylates are used as organic compounds. All compounds except carboxylates have intense color, which limits their use in this area. Salts of carboxylic acids (carboxylates) are the most preferred metal-containing additives due to their high solubility and stability. It should be noted that metal carboxylates are widely used in many areas of human activity. Metal ions and organic ligands combining in one molecule can purposefully change the composi- 
tion and structure of coordination compounds. This opens up opportunities of using them for molecular materials with a wide range of optical, magnetic, electrical, and other functional properties.

Our research of aliphatic acids (carboxylates) derivatives inserted into polystyrene matrix has showed that such compounds are displaced from polystyrene during polymerization. Gadolinium stearate solution in styrene (whose solubility is $50.4 \mathrm{~g} / \mathrm{l}$ ) is distinctly separated into 2 layers during the attempt of polymerization. Aliphatic acid derivatives of more simple structure, as well as derivatives of aromatic acids did not dissolve in styrene.

We could not find publications describing the insertion of gadolinium-containing compounds of aliphatic-aromatic carboxylate acids into a polymer matrix.

Attention should be paid to the advantages of aliphatic-aromatic carboxylic acids because these compounds: are salt-forming reagents, which excludes the possibility of allogenic anions $\left(\mathrm{Cl}-\right.$ and $\mathrm{NO}^{3-}$, etc.) entering into the organic phase, the anions can greatly reduce the light output of the scintillator;

Moreover, carboxylic acids which have aromatic and aliphatic fragments in their structure promote dissolution of carboxylates in styrene and other organic solvents.

There are reasons of carboxylates - acid derivatives, having aliphatic and aromatic fragments in their structure, being selected as promising targets for the present study. Aliphatic-aromatic acids are very similar to fatty acids by their chemical properties, but the presence of aromatic fragment allows to dissolve their derivatives in aromatic compounds, such as benzene, toluene, styrene. It is also valuable that these compounds are able to maintain stability, not only in the monomer solution but in the polymer too, although they have their own peculiarities. Thus, gadolinium carboxylates are inclined to polymerization by carboxylate $\mathrm{COO}^{-}$ groups, which act as bridging ligands. Upon synthesis of the carboxylates, due to their high coordination numbers, the complexes are formed. They contain water molecules in the structure, which can lead to hydrolysis of these compounds. Therefore, such neutral ligands must be inserted in gadolinium complex hydrate. The ligands would supersede the water molecules and fully saturate the coordination sphere of gadolinium.

The problem of gadolinium-containing PS obtaining is discussed in a relatively small
Table 1. Solubility of gadolinium phenylcarboxylates with different quantity of methylene groups in the initial acid molecule

\begin{tabular}{||c|c||}
\hline $\begin{array}{c}\text { Gadolinium phenylcarboxy- } \\
\text { lates hydrate }\end{array}$ & $\begin{array}{c}\text { Solubility of Gd } \\
\text { in styrene, wt. } \%\end{array}$ \\
\hline $\mathrm{Gd}\left(\mathrm{OOC}\left(\mathrm{CH}_{2}\right) \mathrm{C}_{6} \mathrm{H}_{5}\right)_{3} \cdot 2 \mathrm{H}_{2} \mathrm{O}$ & 0.28 \\
$\mathrm{Gd}\left(\mathrm{OOC}\left(\mathrm{CH}_{2}\right)_{2} \mathrm{C}_{6} \mathrm{H}_{5}\right)_{3} \cdot 2 \mathrm{H}_{2} \mathrm{O}$ & 0.52 \\
$\mathrm{Gd}\left(\mathrm{OOC}\left(\mathrm{CH}_{2}\right)_{3} \mathrm{C}_{6} \mathrm{H}_{5}\right)_{3} \cdot 2 \mathrm{H}_{2} \mathrm{O}$ & 2.43 \\
$\mathrm{Gd}\left(\mathrm{OOC}\left(\mathrm{CH}_{2}\right)_{4} \mathrm{C}_{6} \mathrm{H}_{5}\right)_{3} \cdot 2 \mathrm{H}_{2} \mathrm{O}$ & 3.46 \\
\hline
\end{tabular}

number of papers. Usually, gadolinium compounds are added to the triple scintillating compositions containing fluorescent polymer and two fluorescent organic additives (activator and shifter).

For example, authors of [5] described gadolinium containing polystyrene-based scintillator NE120, which was additionally loaded by gadolinium acetylacetonate (Acac) $)_{3}$ Gd with 0.1-0.2 wt. \% by Gd. Light yield of PS with these amounts of gadolinium, is $42-15 \%$ relative to NE1 20 without gadolinium.

The better parameters has polystyrenebased PS with gadolinium nitrate complex and tributyl phosphate or polyvinyl, obtained by low-temperature polymerization $\left(57^{\circ} \mathrm{C}\right)[6,7]$. Light yield of this PS, with 0.25 and 1.9 wt. $\%$ of gadolinium is $72 \%$ and $41 \%$, respectively, of compared to metal-free scintillator.

In [8] for gadolinium containing scintillators, a gadolinium nitrate $\mathrm{Gd}\left(\mathrm{NO}_{3}\right)_{3}$ complex compound is used with hexamethylphosphoramide as a neutral ligand. The light yield of the polymethylmethacrylate (PMMA)-based PS with 3.0 wt. \% gadolinium concentration is $51 \%$ relative to PS that does not contain this element.

Our results $[9,10]$ are show that the use of phenyl carboxylate complexes for gadolinium-containing PS obtaining is more promising in comparison with other compounds of this metal.

In the present work, a number of complexes of gadolinium phenylcarboxylates have been synthesized with different numbers of methylene fragments in the molecule of the parent acid and with different neutral ligands (Table 1).

\section{Experimental}

Synthesis of gadolinium carboxylates was carried out according to our method [11], by the reaction of freshly prepared gadolinium 
hydroxide with the appropriate acid in dry toluene at $75-85^{\circ}$ with simultaneous removal of water released as the result of the reaction. The reaction mixture was cooled and the resulting gadolinium carboxylate is precipitated by hexane, then washed by isopropyl alcohol and dried in air.

Gadolinium complexes with neutral ligands were prepared by gadolinium carboxylate reaction with the appropriate quantity of selected organophosphate compound in dry benzene followed by three solvent distillations in the vacuum.

Structure of the synthesized compounds was confirmed by IR spectroscopy using Fourier infrared spectrometer SPECTRUM ONE (Perkin Elmer).

Thermal stability of the complexes was investigated by Metler-TA 3000 (Switzerland) thermoanalytical system.

Measuring of the PS samples light yield was performed on a scintillation spectrometer in the "CAMAC" standard. Spectrometric tract consisted of a photomultiplier Hamamatzu R1306 and charge-to-digital converter type LeCroy 2249A. Excitation of the samples was carried out by $0.975 \mathrm{MeV}$ energy electrons from $\mathrm{Bi}-207$ source equipped by a collimator. Pulse height distribution was recorded by a photomultiplier tube (PMT) with $50 \mathrm{Ohm}$ anode load. The light yield value of the samples was determined by the maximum of photopeak corresponding to electrons with $E_{e}=0.975 \mathrm{MeV}$. The PS relative light yield $\eta(C)$ was measured relative to that of PS with the same composition but without gadolinium.

\section{Results and discussion}

Investigations of phenyl gadolinium carboxylates solubility in styrene were performed for gadolinium complex hydrate with 1-4 $\mathrm{CH}_{2}$ groups in the ligand. Table 1 presents the experimental results of complexes solubility in styrene, which increases with increasing length of the aliphatic chain in the ligand complex.

Table 2 shows the values of the complexes solubility and dipole moments of organophosphorus compounds that are part of the gadolinium complexes as neutral ligands. As it can be seen from the table, triphenylphosphine oxide (TPPO) provides the highest solubility of the complex due to very large dipole moment $(4.51 \mathrm{D})$ compared to other neutral ligands and due to presence of three aromatic rings in its structure, which have a high affinity to the polystyrene matrix. As follows from the table, the best solubility in styrene has gadolinium 5-phenyl pentanate with triphenylphosphine oxide $\mathrm{Gd}\left(\mathrm{OOC}\left(\mathrm{CH}_{2}\right)_{4} \mathrm{C}_{6} \mathrm{H}_{5}\right)_{3}$.2TPPO, which was the crucial factor for its use as a gadoliniumcontaining compound in the PS.

Detailed analysis of IR spectra was made for 4-phenylbutyric acid and its derivatives.

The spectra of 4-phenylbutyric acid are compared with gadolinium carboxylate hydrate - $\mathrm{Gd}\left(\mathrm{OOC}\left(\mathrm{CH}_{2}\right)_{3} \mathrm{C}_{6} \mathrm{H}_{5}\right)_{3} \cdot 2 \mathrm{H}_{2} \mathrm{O}$ derived from it, which is the starting material for preparation of the complexes with neutral ligand - $\mathrm{Gd}\left(\mathrm{OOC}\left(\mathrm{CH}_{2}\right)_{3} \mathrm{C}_{6} \mathrm{H}_{5}\right)_{3}$.2TPPO. Comparison of the IR spectra of free 4phenylbutyric acid and its corresponding complex showed that under transition from the acid to the complex a split is occur (in the case of $\mathrm{Gd}(\mathrm{III})$ complexes) and shift of the absorption bands $v(\mathrm{C}=\mathrm{O}) / v_{a s}\left(\mathrm{COO}^{-}\right)$to the low-frequency region (Table 3 ) is observed. A wide band of $3368 \mathrm{~cm}^{-1}(\mathrm{v}(\mathrm{OH})$ is observed in the IR spectrum of the initial metal salt $\mathrm{Gd}\left(\mathrm{OOC}\left(\mathrm{CH}_{2}\right)_{3} \mathrm{C}_{6} \mathrm{H}_{5}\right)_{3} \cdot 2 \mathrm{H}_{2} \mathrm{O}$ (Fig. 1 ), which corresponds to the presence of the bound water molecules of the initial carboxylate. Bands corresponding to $v(\mathrm{OH})$ and $\delta\left(\mathrm{H}_{2} \mathrm{O}\right)$ are not observed in the IR spectrum of $\mathrm{Gd}\left(\mathrm{OOC}\left(\mathrm{CH}_{2}\right)_{3} \mathrm{C}_{6} \mathrm{H}_{5}\right)_{3}$.2TPPO (Fig. $2)$. This means that resulting complexes with neutral ligands are water free. Analy-

Table 2. Gadolinium phenylcarboxylates solubility in styrene with different neutral ligands and dipole moments of the neutral ligands

\begin{tabular}{|c|c|c|c||}
\hline Complex & Dipole moment & \multicolumn{2}{|c|}{ Solubility, wt. \% } \\
\cline { 3 - 4 } & NL, D & of the complex & of the Gd \\
\hline Gd(OOC $\left.\left(\mathrm{CH}_{2}\right)_{3} \mathrm{C}_{6} \mathrm{H}_{5}\right)_{3} \cdot 2 \mathrm{TPP}^{*}$ & 2.87 & 8.4 & 1.01 \\
$\mathrm{Gd}\left(\mathrm{OOC}\left(\mathrm{CH}_{2}\right)_{3} \mathrm{C}_{6} \mathrm{H}_{5}\right)_{3} \cdot 2 \mathrm{TPB}^{* * *}$ & 3.0 & 25.0 & 2.8 \\
$\mathrm{Gd}\left(\mathrm{OOC}\left(\mathrm{CH}_{2}\right)_{3} \mathrm{C}_{6} \mathrm{H}_{5}\right)_{3} \cdot 2 \mathrm{TPPO}^{* * *}$ & 4.51 & 42.7 & 4.93 \\
$\mathrm{Gd}\left(\mathrm{OOC}\left(\mathrm{CH}_{2}\right)_{4} \mathrm{C}_{6} \mathrm{H}_{5}\right)_{3} \cdot 2 \mathrm{TPPO}$ & 4.51 & 50.0 & 5.16 \\
\hline
\end{tabular}

"TPP — triphenyl phosphate; "*TBP — tributyl phosphate; ***TPPO — triphenylphosphine oxide. 


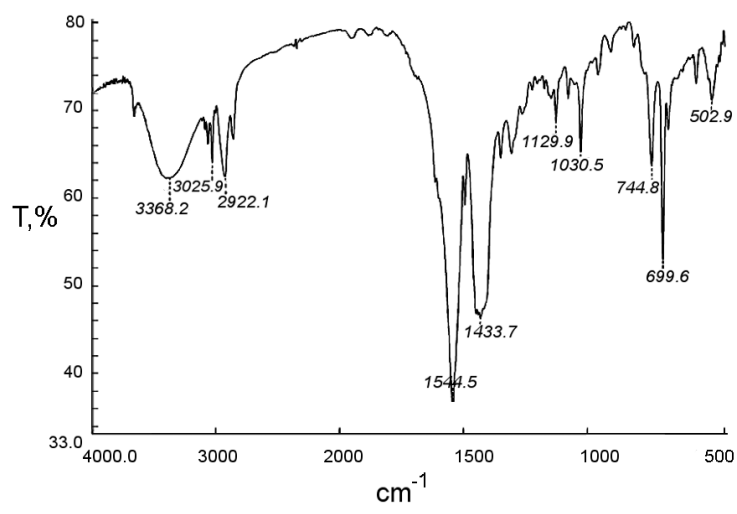

Fig. 1. IR spectrum of gadolinium phenyl butanate hydrate complex $\mathrm{Gd}\left(\mathrm{OOC}\left(\mathrm{CH}_{2}\right)_{3} \mathrm{C}_{6} \mathrm{H}_{5}\right)_{3} \cdot 2 \mathrm{H}_{2} \mathrm{O}$.

sis of positions of the absorption bands of asymmetric vibrations of the carboxyl groups $\left(v_{\mathrm{as}}\left(\mathrm{COO}^{-}\right)\right)$in the spectra of aromatic carboxylates is practically impossible because vibration absorption bands of aromatic rings belonging to the ligands and $\left(\mathrm{v}_{\mathrm{as}}\left(\mathrm{COO}^{-}\right)\right)$ overlap in $1500-620 \mathrm{~cm}^{-1}$ region. Absorption band $v(\mathrm{P}=\mathrm{O}) \mathrm{Gd}\left(\mathrm{OOC}\left(\mathrm{CH}_{2}\right)_{3} \mathrm{C}_{6} \mathrm{H}_{5}\right)_{3} \cdot 2 \mathrm{TPPO}$ is shifted in the low-frequency region by $6.6 \mathrm{~cm}^{-1}$ compared to its position in the spectrum of uncoordinated neutral ligand. Absorption band $v(P=O)$ of the free neutral ligand is also absent in the spectrum of complexes which indicates that the complex $\mathrm{Gd}\left(\mathrm{OOC}\left(\mathrm{CH}_{2}\right)_{3} \mathrm{C}_{6} \mathrm{H}_{5}\right)_{3} \cdot 2 \mathrm{TPPO}$ does not contain impurities of the free neutral ligand. Only valence oscillations of $\mathrm{P}=\mathrm{O}$ are shifted in IR spectra, their position $\delta$ $\left(\mathrm{R}-\mathrm{C}_{6} \mathrm{H}_{5}\right)$ being practically unchanged. Shift of the band $v(P=O)$ confirmed the formation of different-ligand complexes. Table 3 shows the main absorption bands $\left(\mathrm{cm}^{-1}\right)$ in the spectra of 4-phenylbutyric acid and gadolinium complexes $\mathrm{Gd}\left(\mathrm{OOC}\left(\mathrm{CH}_{2}\right)_{3} \mathrm{C}_{6} \mathrm{H}_{5}\right)_{3} \cdot 2 \mathrm{H}_{2} \mathrm{O}$ and $\mathrm{Gd}\left(\mathrm{OOC}\left(\mathrm{CH}_{2}\right)_{3} \mathrm{C}_{6} \mathrm{H}_{5}\right)_{3} \cdot 2 \mathrm{TPPO}$.

The comparison of frequencies in the IR spectra was carried out in accordance with

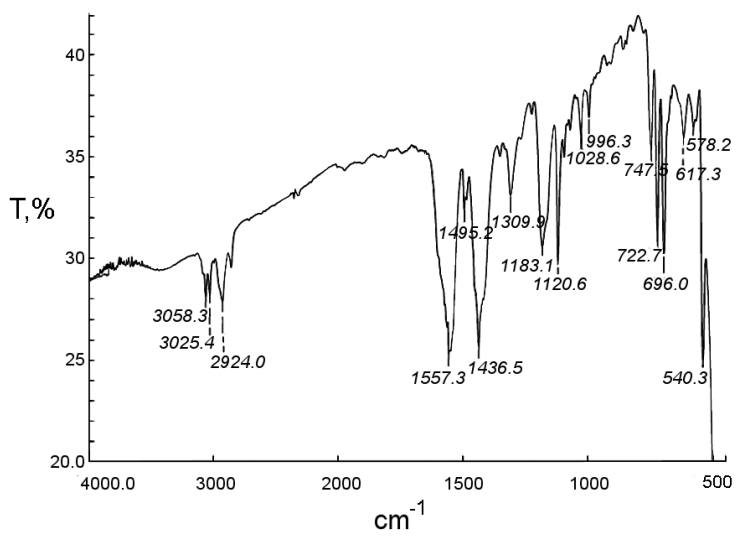

Fig. 2. IR-spectrum of the gadolinium phenylbutanate complex with triphenylphosphine oxide $\mathrm{Gd}\left(\mathrm{OOC}\left(\mathrm{CH}_{2}\right)_{3} \mathrm{C}_{6} \mathrm{H}_{5}\right)_{3}$.2TPPO.

the literature data $[13,14]$. Thus, the data of IR-spectroscopy for the obtained complexes correspond to their attributed compositions.

It should be noted that our researches of the determination of water molecules by the Fischer method showed the presence of 2 water molecules in the hydrated complexes. Determination of water showed the presence of $0.2 \%$ water molecules in $\mathrm{Gd}\left(\mathrm{OOC}\left(\mathrm{CH}_{2}\right)_{3} \mathrm{C}_{6} \mathrm{H}_{5}\right)_{3}$.2TPPO compound which can be attributed to adsorbed water on the compound surface.

We have investigated thermal stability of the studied compounds to select the optimum conditions of polymerization on the example of gadolinium phenylbutirate in argon atmosphere. Derivatogram in Fig. 3 shows that the complex is stable up to $75^{\circ} \mathrm{C}$ temperature, and the fact that the complex with neutral ligands does not contain water molecules.

To select of the optimal conditions of gadolinium-containing scintillators obtaining we chosed the cross-linking agent-4,4'diphenyl-bis(methylene-2-methacrylate)

Table 3. Main absorption bands $\left(\mathrm{cm}^{-1}\right)$ of 4-phenylbutyric acid complexes $\mathrm{Gd}\left(\mathrm{OOC}\left(\mathrm{CH}_{2}\right)_{3} \mathrm{C}_{6} \mathrm{H}_{5}\right)_{3} \cdot 2 \mathrm{H}_{2} \mathrm{O}$ and $\mathrm{Gd}\left(\mathrm{OOC}\left(\mathrm{CH}_{2}\right)_{3} \mathrm{C}_{6} \mathrm{H}_{5}\right)_{3} \cdot 2 \mathrm{TPPO}$ in the IR spectra

\begin{tabular}{||c|c|c|c|c|c||}
\hline \hline Compound & $\begin{array}{c}v_{a s}\left(\mathrm{COO}^{-}\right. \\
) / v(\mathrm{C}=\mathrm{O})\end{array}$ & $v(\mathrm{C}-\mathrm{H})$ & $v(\mathrm{P}=\mathrm{O})$ & $-\mathrm{CH}_{2}-$ & $v(\mathrm{OH})$ \\
\hline $\mathrm{C}_{6} \mathrm{H}_{5}{ }^{-}\left(\mathrm{CH}_{2}\right)_{3}{ }^{-} \mathrm{COOH}$ & 1692.7 & 3062.7 & & $1408.6 ;$ & 3421.2 \\
& & & & $1438.2 ;$ & 1454.3 \\
$\mathrm{Gd}\left(\mathrm{OOC}\left(\mathrm{CH}_{2}\right)_{3} \mathrm{C}_{6} \mathrm{H}_{5}\right)_{3} \cdot 2 \mathrm{H}_{2} \mathrm{O}$ & 1544.5 & 2922.1 & & 1433.7 & 3368.2 \\
$\mathrm{Gd}\left(\mathrm{OOC}\left(\mathrm{CH}_{2}\right)_{3} \mathrm{C}_{6} \mathrm{H}_{5}\right)_{3} \cdot 2 \mathrm{TPPO}$ & $1436.5 ; 1557.3$ & 3058.3 & 1183.1 & & \\
TPPO & & 3951 & 1192 & & \\
\hline
\end{tabular}




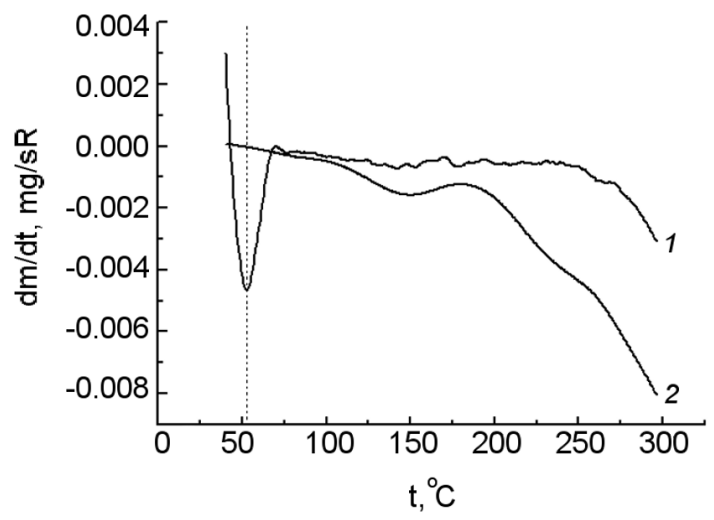

Fig. 3. Thermal stability of the gadolinium complexes. $1-\mathrm{Gd}(\mathrm{PhB})_{3} \cdot 2 \mathrm{H}_{2} \mathrm{O} ; 2$ $\mathrm{Gd}(\mathrm{PhB})_{3} \cdot 2 \mathrm{TPPO}$.

(DPDMA). This enabled reducing temperature of the polymerization and forming a cross-linked structure, which allowed distributing the gadolinium complex throughout the volume of the scintillator.

Using the cross-linking agent DPDMA has two reasons.

At first, DPDMA has high reactivity and, as our researches showed, combined with a polymerization initiator 2,2'-azodiizobutironitril (AIBN) reduces the polymerization temperature to $60^{\circ} \mathrm{C}$ of the resin composition and reduces the duration of the process of polymerization to $48 \mathrm{~h}$. Secondly, it significantly lowers the possibility of oxidation and staining of the polymer, resulting in clear, colorless PS with high scintillation efficiency (SE) and with high content of gadolinium compared to known analogues.

In addition, cross-linked polymers have improved thermal and mechanical properties, which greatly facilitate the process of mechanical treatment and improve the surface quality of the finished PS.

As a result of our research it was found that for optimal rate of scintillation mixture polymerization at $60^{\circ} \mathrm{C}$ temperature, the content of the cross-linking agent (DPDMA) and the initiator (AIBN) must be in the range of 0.5 to 2 wt. \% for DPDMA and 0.02 to 1 wt. $\%$ for AIBN. Changing the content of these ingredients leads to a small change in the total time of the polymerization process in this range, and has little influence on the scintillation characteristics of the finished PS.

As it known, the introduction of the cross-linking agent to styrene leads to modification of the polymer structure. Scintillator samples of linear and cross-linked gad-

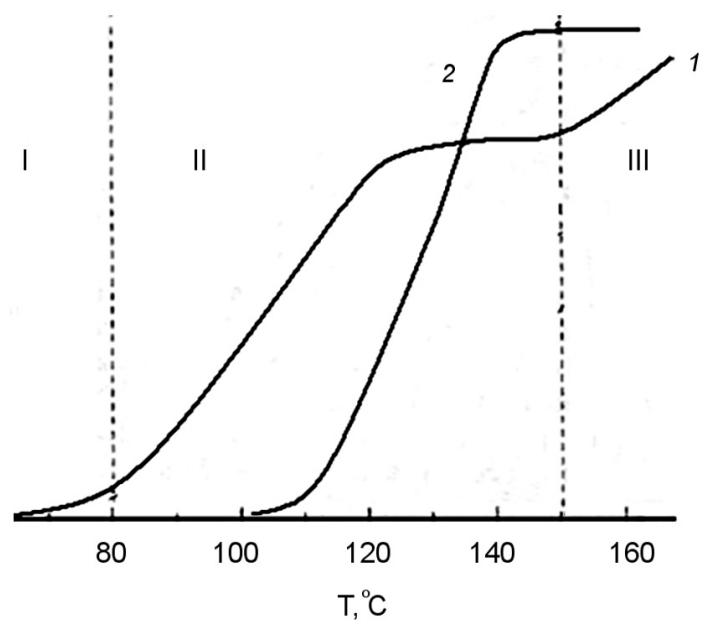

Fig. 4. TM curves of linear (curve 1) and cross-linked gadolinium containing (curve 2) polystyrene scintillators. Concentration of $\mathrm{Gd}$ and DPDMA was 1 wt. \% working load$9 \mathrm{kgf} / \mathrm{cm}^{2}$.

olinium containing polystyrene were investigated by thermomechanical analysis by Hoppler consistometer, which enabled determining the temperature of aggregates phase transition. Thermo-mechanical curves of the cross-linked and linear gadolinium-containing polystyrene scintillators are compared in Fig. 4. The thermo-mechanical curve for linear polystyrene (1) reflects the glass (I), highly elastic (II) and viscous flow (III) physical states. The glass transition and fluidity temperatures are equal, respectively, to $80^{\circ} \mathrm{C}$ and $150^{\circ} \mathrm{C}$.

Area of highly elastic deformation on the thermo-mechanical curve for the gadolinium containing cross-linked polystyrene scintillator (Fig. 4, curve 2) indicates formation of the cross-linked structure with the glass transition temperature of $110^{\circ} \mathrm{C}$.

We also studied using Vickers method the microhardness of the samples of amorphous and cross-linked gadolinium-containing polystyrene. Microhardness of the samples of gadolinium containing cross-linked scintillator is $218 \mathrm{MPa}$. Hardness and strength of the material are increased in comparison with microhardness of the linear polystyrene scintillator (210 $\mathrm{MPa})$.

\section{Conclusions}

So, in the framework of this work gadolinium carboxylates fatty aromatic acids containing from 1 to 4 methylene groups, and their complexes with different neutral ligands were synthesized and investigated. 


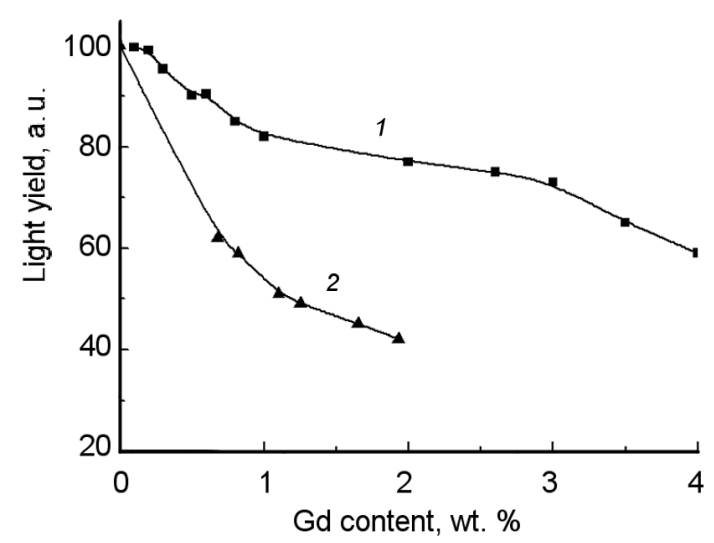

Fig. 5. Dependences of relative light yield $\eta$ $(C)$ on the content of $\mathrm{Gd}$ in Gd-containing PS, $1-\mathrm{Gd}(\mathrm{PhV})_{3} \cdot 2 \mathrm{TPPO} ; 2-\mathrm{Gd}\left(\mathrm{NO}_{3}\right)_{3} \cdot 3 \mathrm{TBP}$.

The optimal conditions were selected for the polymer samples preparation and their thermomechanical properties were studied.

Polystyrene scintillator containing $\mathrm{Gd}\left(\mathrm{OOC}\left(\mathrm{CH}_{2}\right)_{4} \mathrm{C}_{6} \mathrm{H}_{5}\right)_{3}$.2TPPO complex is obtained. Light yield of the resulting sample of PS with 1.0 wt. $\%$ of Gd was $82 \%$ relative to the gadolinium-free scintillator (Fig. 5).

\section{References}

1. M.Apollonio et al., J.Eur.Phys., 5, 331 (2003).
2. C.He, S.J.Lippard, J.Am.Chem.Soc., 120, 105 (1998).

3. W.Ruttinger, G.C.Dismukes, Chem.Rev., 97, N1 (1997).

4. G.I.Dzhardimalieva, A.D.Pomogailo, Russian Chemical Reviews, 77, 270 (2008).

5. I.B.Gzirr, Nucl.Instr.Meth., 108, 613 (1973).

6. US Patent.6.544.422 (2003).

7. Z.W.Bell, G.M.Brown, C.H.Ho et al., X-Ray and Gamma-Ray Detectors and Applications IV, in: Proc. of SPIE, 4784, 150 (2002).

8. V.B.Brudanin, V.I.Bregadze, N.A.Gumdorin et al., Particls and Nucl. Lett., 109, 69 (2001).

9. P.N.Zhmurin, V.N.Lebedev, A.I.Bedrik, Patent of Ukraine, a201201449 (2012).

10. A.I.Bedrik, E.C.Velmozhnaya, P.N.Zhmurin et al., Functional Materials, 18, 470 (2011).

11. O.I.Bedryk, O.S.Velmozhna, P.M.Zhmurin, Patent of Ukraine, 98259 (2012).

12. G.Ya.Novikova, I.R.Barabanov, L.V.Bezruk, J. Inorg. Chem., 54, 1143 (2009).

13. K.Nakamoto, Infrared and Raman Spectra of Inorganic and Coordination Compounds: Theory and Applications in Inorganic Chemistry, Moscow, New York (1991).

14. L.A.Kazitsyna, N.B.Kupletskaya, Primenenie UF spectroscopii v Organicheskoy Chimii, Higher School, Moscow (1971) [in Russian]. 